\title{
Model Driven PID Controller in Water Heater System
}

\author{
Tommy Hondianto, Erwin Susanto, Agung Surya Wibowo
}

Department of Electrical Engineering, Telkom University, Bandung, Indonesia

\section{Article Info}

Article history:

Received Dec 7, 2015

Revised May 17, 2016

Accepted May 30, 2016

\section{Keyword:}

Model driven PID

RTD

Water heater

\begin{abstract}
PID controller has been widely used as one of the basic property controllers in industry. However, tuning PID parameters is not simple and also has a few problems in handling slow response systems, such as boiler. Therefore, the Model Driven PID (MD PID) control is designed for solving these problems, especially for plants or processes with slow response. The MD PID is using the model of the plant itself as the basic model of the controller. In this research, we will show the performance of water heater system step response with MD PID controller compared to the conventional PID controller (PI controller). The MD PID closed-loop system is expected to give fast response, stable, and no overshoot.
\end{abstract}

Copyright (C) 2016 Institute of Advanced Engineering and Science. All rights reserved.

\section{Corresponding Author:}

Tommy Hondianto, Department of Electrical Engineering, Telkom University, Jln. Telekomunikasi, Terusan Buah Batu, Bandung 40257, Indonesia.

Email: tommyh@students.telkomuniversity.ac.id

\section{INTRODUCTION}

One of the most common controller used is PID controller. PID controller is a classic controller that have been widely used to control a process, such as motor speed control, positioning control, level control, temperature control, etc. However, due to its simple stucture, PID controller also bring some issues in different areas. To control a process with relative slow response, such as boiler, it will leave some overshoot for a long period. Therefore, the Model Driven PID (MD PID) controller is presented to handle slow response process to minimizing overshoot as the expected actual point value is rising to the set point. MD PID controller also capable to control non-stable system and oscillation process. MD PID controller is also gives more simple control tuning properties.

MD PID controller is proposed by Toshiba Research Team, it is designed by combining Model Driven Control (MDC) controller system, PD feedback, Internal Model Control (IMC), and set point filter. The design approach techniques of MD PID controller is different compare to conventional PID that commonly using the Ziegler-Nichols [1],[2] method to defined the control tuning parameters.

In this research, we designed the MD PID controller system and simulated it in water heater system. The purposed was to analyzed the MD PID controller system with a plant or process and compared to the conventional PID controller. We used physic approach to design the transfer function model of the water heater system. Resistance Temperature Detector (RTD) type PT100 with two wires is used as the sensor of water heater system for measured the value of the temperature as the present value (PV) or output and as the feedback value of the closed-loop system. The results of the step response were analyzed and compared to the step response of the conventional PID controller. The MD PID stability analysis, step response matlab simulation of the system, and MD PID real time result are presented. 


\section{RESEARCH METHOD}

The research chronological order in this paper are design the system model of the controller, stability analysis, sensor configuration, and simulation analysis.

\subsection{Hardware and Software}

Figure 1 shows the overall system configuration used for the research. The microcontroller and PC connected by using serial communication. The read temperature plotted in Matlab software. The output from microcontroller is PWM to triggering the heating procress base on the duty cycle. Temparature sensor (RTD) is used to acquired some actual temperature data trajectory from the water heater system to be analyzed.

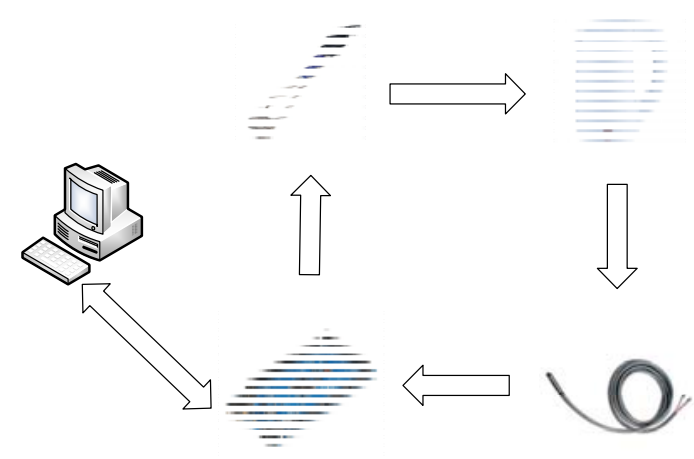

Figure 1. System Configuration for Research

\subsection{PID Controller}

MD PID controller has three parts, PD feedback compensator, main controller, and set point filter [3]. Each parts have different functions. The tuning parameters used are $\lambda$ and $\alpha$. MD PID controller block diagram are shown in Figure 2.

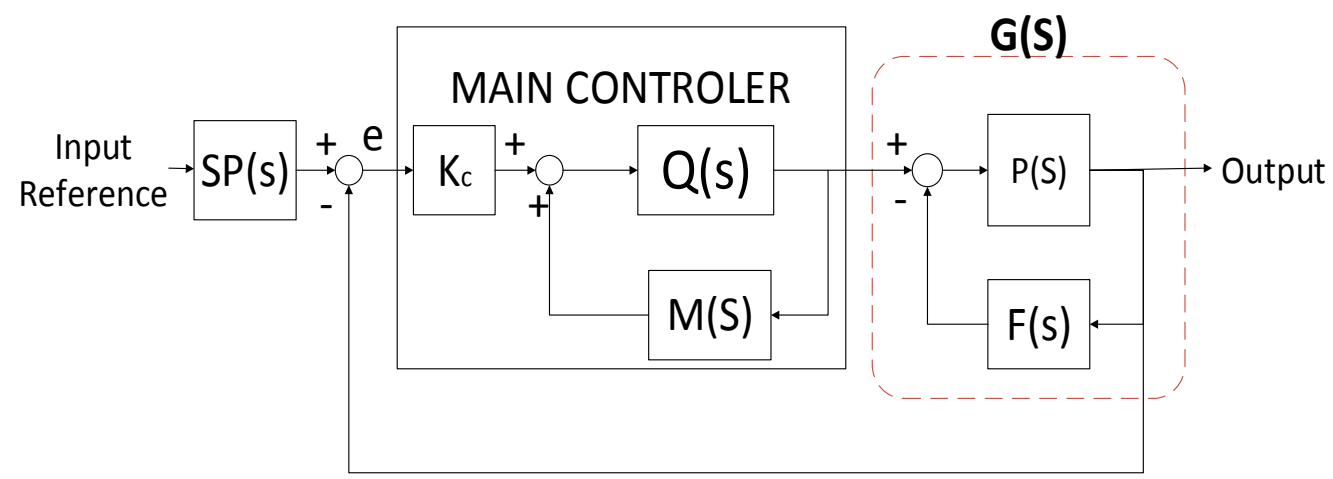

Figure 2. Model Driven PID Block Diagram

\subsubsection{PD Feedback Compensator}

PD feedback block F(s) is used for stabilize the plant or process $\mathrm{P}(\mathrm{s})$ and design the transfer function $\mathrm{G}(\mathrm{s})$ in first order with dead time model as in (1). The transfer function of the Proportional-Derivative (PD) block $\mathrm{F}(\mathrm{s})$ is shown in (2).

$$
G(s)=\frac{P(s)}{1+P(s) F(s)}
$$




$$
F(s)=\frac{K_{f}\left(1+T_{p} s\right)}{1+\kappa T_{i} s}
$$

By using PD feedback compensantor, the plant is compensated into FOTD (First Order, Time Delay) model as expressed in (3).

$$
G(s) \cong \frac{R e^{-2 s}}{1+T s}
$$

The parameters constant $\mathrm{K}, \mathrm{T}$, and $\mathrm{L}$ are gain, time constant, and dead time. These parameters were used for modeling the MD PID controller system. In this research, the value of $\mathrm{K}, \mathrm{T}$, and $\mathrm{L}$ were defined by using the model matching Kitamori method [4]. By using this method, the transfer function of the plant have to be known. is defined.

In this research, based on the water heater transfer function model [5] as in (4), the transfer function

$$
P(s)=\frac{k}{C s+\frac{1}{R}} \propto \frac{K_{\bar{\zeta}}}{T_{s} z+1} \sigma^{-n}
$$

Variables $\mathrm{k}, \mathrm{C}$, and $\mathrm{R}$ are heater constant, thermal capacitance, and thermal resistance. For

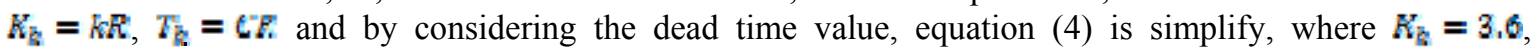
$\tau_{5}=77.88$, and $\tau=30$.

By using the model matching Kitamori method, the parameters value from (3) are defined, where the parameters value are $E=2.237, T=33.02$, and $L=34.4$.

These parameters from block $6(0)$ will be the reference for all the system closed-loop parameter in main controller and set point filter.

\subsubsection{Main Controller and Set Point Filter}

Main controller consisted of Q-filter second order $Q(s)$ and first order model with dead time $M(s)$ as the positive feedback. The equation of main controller is shown in (5) and (6).

$$
\begin{aligned}
& Q(s)=\frac{\left(1+T_{c} s\right)\left(1+\alpha T_{c} s\right)}{\left(1+\lambda T_{c} s\right)^{2}} \\
& M(s)=\frac{\theta^{-\nu_{2} s}}{1+T_{c} s}
\end{aligned}
$$

The Q-filter second order give the control system the stronger ability to handle disturbance of the system and input reference value changes without overshoot. Parameters $\mathrm{K}_{c}, \mathrm{~T}_{c}$, and $\mathrm{L}_{\mathrm{c}}$ are gain, time constant, and dead time controller from the acquired parameters from $\mathrm{G}(\mathrm{s})$ that have a following relation;

$$
K_{\varepsilon}=1 \ell K, T_{c}=T, L_{\varepsilon}=L
$$

Set point filter equation is expressed in (7).

$$
S P(g)=\frac{1+\lambda T_{c} g}{1+\alpha T_{c} g}
$$

\subsubsection{Tuning Parameters}

Parameters $\lambda$ and $\alpha$ are tuning parameters for MD PID controller. Tuning parameter $\lambda$ (lamda) is used for tuned the speed response of the closed-loop system and tuning parameter $\alpha$ (alpha) for disturbance regulation performance.

The optimal $\alpha$ can be obtained as in (8), by canceling the slowest pole of the process and a zero of the controller concerning the $\alpha[6]$. 
$\alpha=1-(1-\lambda)^{2} \operatorname{sep}\left(-E_{\sigma} / T_{\varepsilon}\right)$

In this research, the tuning parameters for MD PID controller for water heater real-time simulation are $\lambda=\alpha=1$. The conventional PID controller we used as comparison is Proportional-Integral (PI) controller as shown in (9). Adding derivative parameter to the controller is not required. The water heater system response is moving slowly, so the predictive control from derivative parameter wont give any significance changes.

The parameters of the PI controller we used are $K p=0.2178$ and $K l=0.003866$. Where 'u' is the output controller and ' $\mathrm{e}$ ' is error.

$$
F(g)-\frac{U(g)}{E(g)}-K_{p}+\frac{K_{p}}{g}
$$

\subsection{System Stability}

In this paper, we analyzed MD PID controller by using root locus method. The control system dead time value are approximated by using pade approximation [7] to define the root locus trajectory. By approximate the exponential function, root locus trajectory can be define as shown in (10). The order of the approximate exponential function is $\mathrm{n}=10$, so the closed loop transfer function can be expressed in (11). Where $a_{k}$ and $b_{k}$ are numerator and denumerator coeficient respectively.

$$
\begin{aligned}
& g^{z}=R(g)=D(z)^{-1} \operatorname{DV}(z) \\
& N(v)-\sum_{n=0}^{\infty} \frac{n !}{(2 n) !} 2^{n} \\
& D(\sigma)=\sum_{n=0}^{\infty} \frac{n !}{(2 n) !}(\pi)^{n}
\end{aligned}
$$

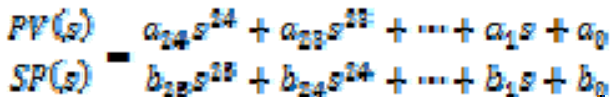

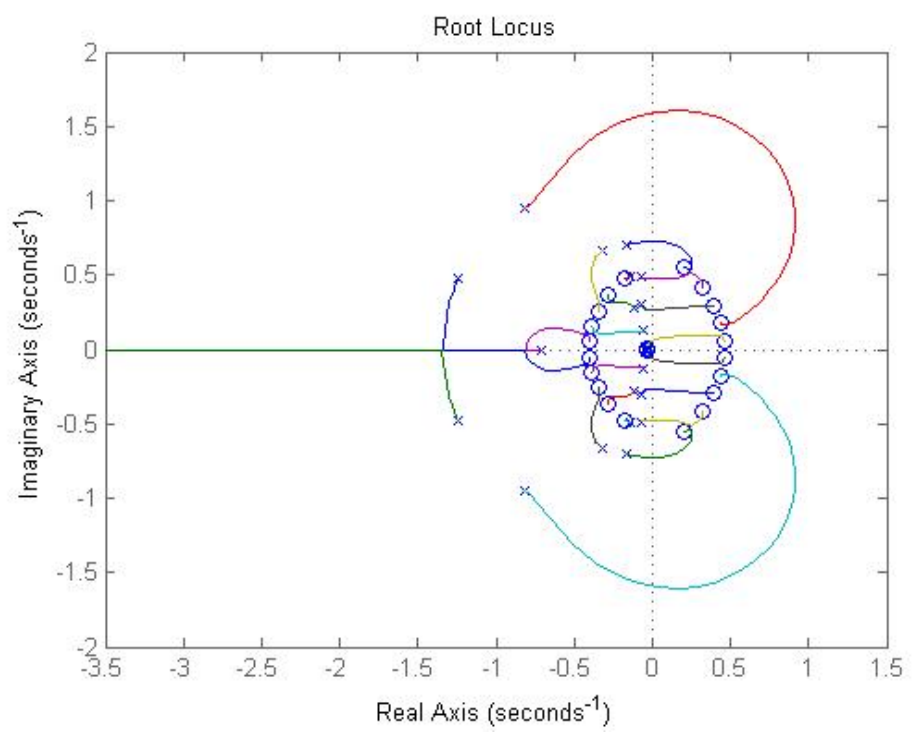

Figure 3. Model Driven PID Root-Locus Stability 
From the closed-loop transfer function model of Model Driven PID controller, the root-locus graph is shown in Figure 3. Based on the root-locus figure, we conclude that the system performance are normally stable because all of the poles of the control system are on the left side of imaginary axis $(s<0)$ [8],[9].

\subsection{Resistance Temperature Detector/PT100}

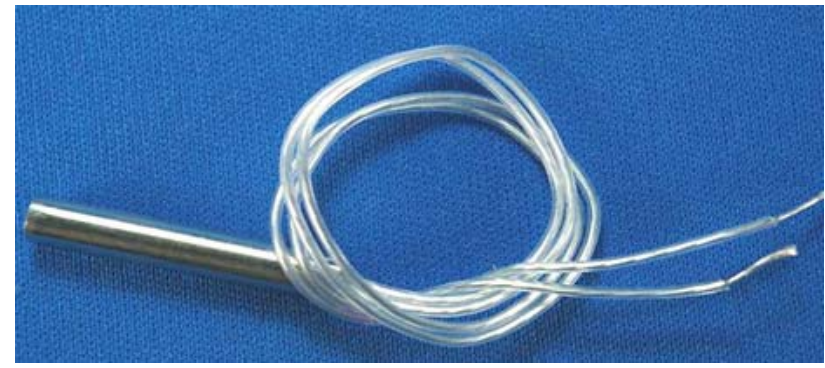

Figure 4. RTD PT100 Sensor Two Wire

RTD is a device for read the temperature value by measuring the resistance of the electrical cable. The material of RTD sensor is divide into three types, cooper, nickel, and platinum. These three metal types have variance resistance. Platinum has the measurement range to $650^{\circ} \mathrm{C}$, cooper $120^{\circ} \mathrm{C}$, and nickel $300^{\circ} \mathrm{C}$.

In this research, we use the RTD type PT100 with two wires. There are also other wire configurations available with three and four wires [10]. PT100 sensor has the platinum material with resistance $100 \Omega$ at the reference temperature $0^{\circ} \mathrm{C}$. The value of the sensor resistance changes and rise up $0.385 \Omega$ for each $1^{\circ} \mathrm{C}$ increment to the measured temperature. In (12) the equation of the linlearlty measurement of the sensor is shown. Constant $\mathrm{T}$ is the measured temperature, $\mathrm{T}_{\text {ref }}$ is the reference temperature that equal to $0^{\circ} \mathrm{C}$.

$$
R_{\text {prinค }}=100+\left[\left(T-T_{\text {ref }}\right)=C \times 0.385\right][\Omega]
$$

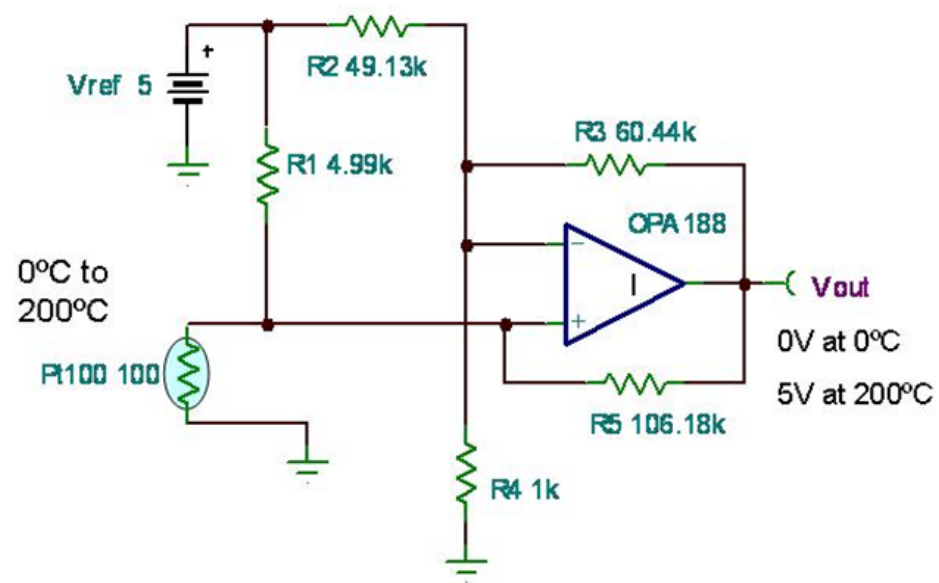

Figure 5. PT100 Circuit Configuration [11]

The PT100 sensor has dynamic resistance depending on the measured temperature, therefore, it is needed a specific circuit configuration (Figure 5) for measured the temperature value by converted the sensor resistance value into voltage and also can keep its linearity. The circuit configuration is combining the Wheatstone bridge and Operational Amplifier (Op-Amp) as differential amplifier. The measurement range of the sensor linearity is $0^{\circ} \mathrm{C}-200^{\circ} \mathrm{C}$ for voltage value $0-5 \mathrm{~V}$. The sensor circuit results to its linearity are shown in Table 1. 


\begin{tabular}{cccc}
\multicolumn{4}{c}{ Table 1. Sensor Linearity } \\
\hline Temp ${ }^{\circ} \mathbf{C}$ & RTD (V) & Vout (V) & Nonlin. \\
\hline 0 & 0.09814 & 0.00000 & $0.000 \%$ \\
20 & 0.10612 & 0.49984 & $-0.003 \%$ \\
40 & 0.11409 & 0.99978 & $-0.004 \%$ \\
60 & 0.12207 & 1.49981 & $-0.004 \%$ \\
80 & 0.13005 & 1.99989 & $-0.002 \%$ \\
100 & 0.13803 & 2.50000 & $0.000 \%$ \\
120 & 0.14601 & 3.00011 & $0.002 \%$ \\
140 & 0.15399 & 3.50020 & $0.004 \%$ \\
160 & 0.16197 & 4.00022 & $0.004 \%$ \\
180 & 0.16995 & 4.50017 & $0.003 \%$ \\
200 & 0.17792 & 5.00000 & $0.000 \%$ \\
\hline
\end{tabular}

\section{RESULTS AND ANALYSIS}

In this section, we explained the controllers' performances results base on real-time data acquisition and also on mathematical analysis in matlab software. We compare both MD PID controller and conventional PID controllers (PI), and also MD PID real-time result.

\subsection{PID vs PI Controller Simulation}

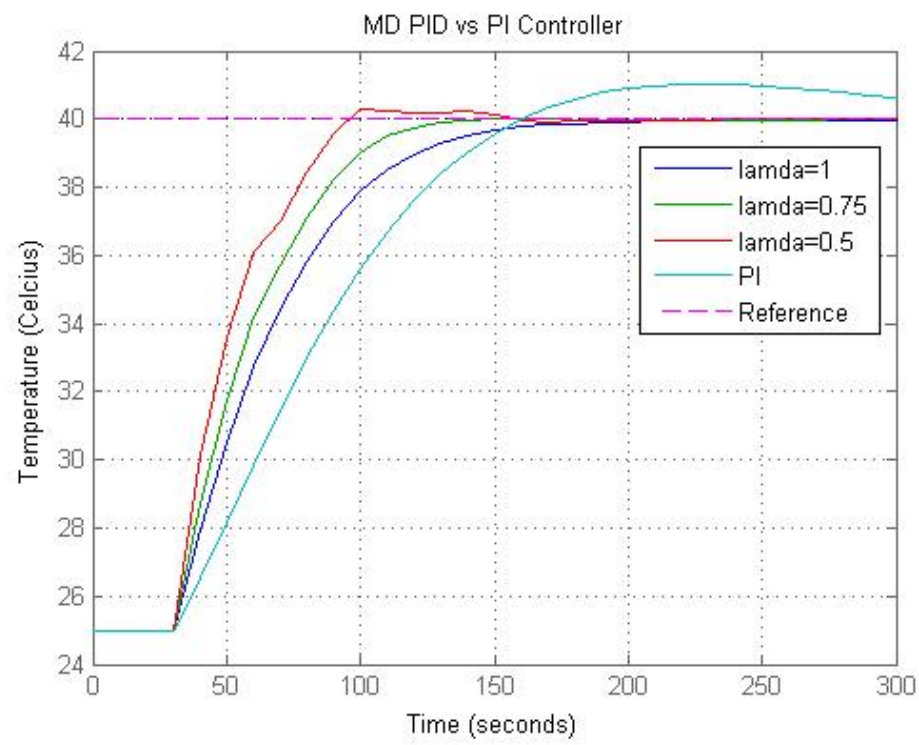

Figure 6. MD PID vs PI Controller

The comparison of MD PID and PI controller are shown in Figure 6. The simulation are conditionaly state where the temperature of water heater system is initially at $25^{\circ} \mathrm{C}$ and the desired output of the water temperature is $40^{\circ} \mathrm{C}$. The time range of the simulation is from $0-300$ seconds. The PI controller are simulated based on (9) and the parameters $K_{p}$ and $K_{i}$ are defined. MD PID controller are simulated and also changing the speed tuning parameter $(\boldsymbol{\lambda})$ to analyze the differences of simulation results. For more details of the simulations data, Table 2. are shown.

Table 2. MD PID and PI Controller Step Response Analysis

\begin{tabular}{ccccc}
\hline Step Info & PI & $\boldsymbol{\lambda}=\mathbf{1}$ & $\mathbf{M D}$ & $\boldsymbol{\lambda}=\mathbf{0 . 7 5}$ \\
\hline Rise-Time & $92.0164 \mathrm{~s}$ & $74.5786 \mathrm{~s}$ & $59.4621 \mathrm{~s}$ & $47.7017 \mathrm{~s}$ \\
Settling Time & $351.0197 \mathrm{~s}$ & $152.7577 \mathrm{~s}$ & $117.9946 \mathrm{~s}$ & $106.7900 \mathrm{~s}$ \\
Overshoot & $6.8929 \%$ & $0 \%$ & $0.0645 \%$ & $2.3073 \%$ \\
Undershoot & 0 & 0 & 0 & 0 \\
Peak & 1.0689 & 0.9994 & 1.0006 & 1.0231 \\
\hline
\end{tabular}


Table 2 shown that MD PID and PI controller reached the desired output value almost at the same time, but PI controller result shown some overshoot for a longer period. This is shown from the large number of the settling time. PI controller also reach a higher peak amplitude than MD PID controller. Selecting smaller speed tuning parameters $(\lambda)$ for MD PID controller also provide the system respons to be faster, but the stability decrease. In spite, the step respons are still tougher than PI controller base on Figure 6 . This can be occured by the lacked of the random selected parameters in the conventional PID controllers.

\subsection{Water Heater Result with MD PID}

The water heater system result by using MD PID controller are shown in Figure 7. The simulation of water heater system is use $40^{\circ} \mathrm{C}$ as desired output and time range $0-450$. In this research, we tuned the MD PID controller $\alpha=\lambda=1$. The water heater real time system is analyzed by plotting the real time data in matlab software.

It is shown from Figure 7, the step response shown stable performance of temparature control when the actual temparature value reached desired temperature value. There is $3.4 \%$ overshoot in this result available and reached the peak at $41.36^{\circ} \mathrm{C}$. The rise time of the step response is 110.1 seconds.

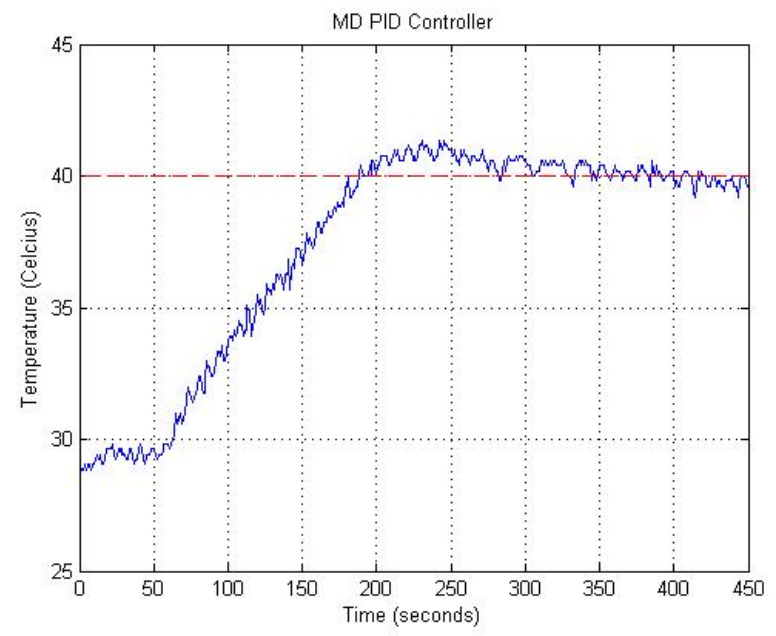

Figure 7. MD PID Real-Time Plot

\section{CONCLUSION}

MD PID and PI controller have been simulated in a designed water heater system. By adding Qfilter block second order, first order model with dead time, set point filter, and PD feedback block diagram, MD PID controller has shown better results compare to the simulation with conventional PID controller (PI) based on the rise time, settling time, and overshoot to control a slow response system.

However, MD PID controller design process, it has to be carefully designed. System modeling is required to define the controller parameters to be apply in controller. For conventional PID, trial and error method to define controller parameters is available without knowing the system model. It can be defined by using the knowledge of common characteristic of proportional, integrator, and differential features.

Next, MD PID controller in this simulation proofed to be able to gives satisfactory response that are more stable to the set point for handling plant or process with relatively slow and less overshoot based on the stability analysis are shown.

For further researches, a more flexible method by using MD PID controller for multivariable control system can be implemented. In this research, we shown a real time simulation of a simple SISO (SingleInput, Single-Output) system. Controlling MIMO (Multi-Input, Multi-Output) system with MD PID controller will bring more complexity to the algorithms but still holds some of the MD PID features.

\section{ACKNOWLEDGMENTS}

The author wishes to acknowledge Dr. Amin Suyitno, Muroran Institute of Technology, for the topic idea and some useful discussion with author. 


\section{REFERENCES}

[1] K. J. Astrom and T. Hagglund, “Advance PID Control," Research Triangle Park, USA: ISA-International, System, and Automation Society, 2006.

[2] O. Ibrahim, et al., "Performance Evaluation of Three PID Controller Tuning Algortihm on a Process Plant," International Journal of Electrical and Computer Engineering, vol. 5, pp. 1075-1082, 2015.

[3] T. Shigemasa and M. Yukitomo, "Model-Driven PID Control System, its properties and multivariable application," Proceedings of 8th Annual IEEE Advance Process Control Applications for Industry Workshop, Vancouver, Canada, 2004.

[4] T. Shigemasa, et al., "A Model-Driven PID Control System and its Case Studies," Proceedings of the 2002 IEEE International Conference on Control Applications, Glasgow, pp. 571-576, 2002.

[5] H. A. Suthar and J. J. Gadit, "Modelling and Analysis of the Simple Water Heater System," International Journal of Electrical and Computer Engineering, vol.1, pp. 49-52, 2011.

[6] T. Shigemasa, et al., "A Tdof Pid Control System Design by Referring to the Md-Pid Control System and Its Sensitivities," European Control Conference, Zurich, 2013.

[7] G. H. Golub and C. F. V. Loan, "Matrix Computations," 3rd ed., London, England: The Johns Hopkins University Press, 1996.

[8] K. Ogata, "Modern Control Engineering," 4th ed., New Jersey, USA, Prentice Hall, 2002.

[9] A. Suyitno, et al., "Variable-Structured Robust Controller by Fuzzy Logic for Servomotors," IEEE Transactions on Industrial Electronics, vol. 4, pp. 80-88, 1993.

[10] H. A. Suthar and J. J. Gadit, "Low Cost Signal and Conditioning Technique for RTD measurement," International Journal of Nano Devices, Sensors, and Systems, vol. 1, pp. 19-24, 2012.

[11] B. Trump, "Analog linearization of resistance temperature detectors," Texas Instruments: Analog Applications Journal, pp. 21-24, 2011.

\section{BIOGRAPHIES OF AUTHORS}
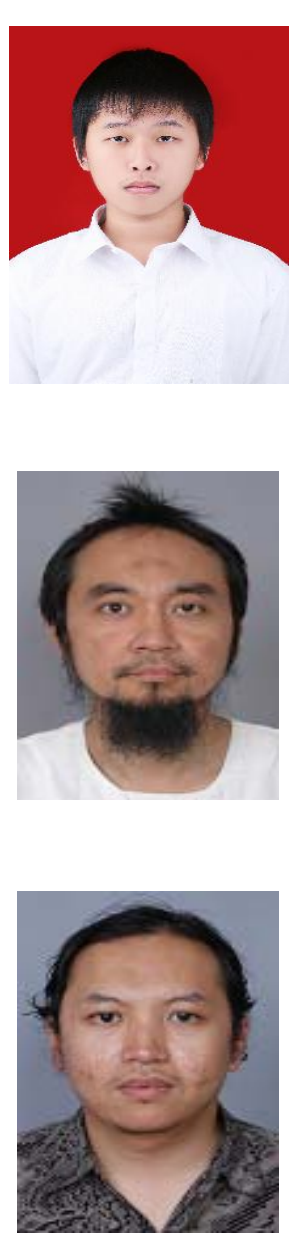

Tommy Hondianto. He is a student at Telkom University. He recieved his B. Eng (ST) in Electrical Engineering from Telkom University, Indonesia in 2015. His research interest is Control System and Instrumentations.
Dr. Erwin Susanto. Dr Erwin Susanto received the Ph. D degree from Kumamoto University, Japan in 2012. Currently, he is an Assistant Professor at School of Electrical Engineering, Telkom University. Since 2014, he has been a head of Electronic System Research Group. His research interest is Control System theory and applications.
Agung Surya Wibowo. He received the master degree from STEI ITB, Bandung in 2012. Currently, he is a lecturer School of Electrical Engineering, Telkom University. His research interest is Control System theory and applications. 